\title{
Gathering in threads in the insensible global world: the wicked problem of globalisation and science education
}

\author{
Lyn Carter
}

Received: 20 December 2010/ Accepted: 20 December 2010/Published online: 2 February 2011

(C) Springer Science+Business Media B.V. 2011

I pulled a loose thread,

I gather you in,

Discovered I could ...

Insensible, Mandalay (1998)

This volume of CSSE brings to a close the three edition special series on globalisation and science education spread out over the past several years. Beginning in 2008 with Volume 3 , Number 1, the intention of the series was to help address the paucity of science education scholarship that investigated globalisation, that meta-narrative and practice of our times, in which science education is embedded. The first volume focussed on "why and how the notion of identity can be helpful in tracing the trajectories of people teaching and learning science" (Lee and Roth 2008 p.14) and the second produced last year (Volume 5, Number 2) worked the theme of globalisation as "authors explored ways in which individual teachers, students, and their communities were experiencing the affects of globalization on science education within differing local contexts" (Martin 2010 p. 264). The collection makes an interesting body of work, which exemplifies how globalisation shapes and abounds within science education just as science education circulates and perpetuates globalisation.

To recap, we can understand globalisation as the recent transformations of information, capital, labour, markets, communications, technological innovations and ideas stretching out across the globe that have become fundamental for constructing our understandings of the contemporary world. The everyday consciousness is now one of a global imaginary, making us feel connected to far-flung places and events. Gerard Delanty (2000) is amongst the many theorists who broadly group the various characterisations of globalisation into political economic transformations and sociocultural changes. Within the former, the processes of convergence foster an increasingly hegemonic homogenisation embodied in the growth of neoliberal market ideologies and of

L. Carter $(\bowtie)$

School of Education, Australian Catholic University, Melbourne Campus, Melbourne, VIC, Australia e-mail: lyn.carter@acu.edu.au 
supra national regulation, the extension of the enterprise form to scientific and technological innovation, and the expansion of Western-style capitalism and culture. These ideas and practices have been applied to education (and hence science education), through the adoption of market regulatory procedures like standards, curriculum and teacher standards for example, funding arrangements, the introduction of Charter schools with their focus on individualisation, and test performance and hierarchical league tables that lead to closure for underperforming schools. This neoliberal reform of education and its impact on teaching and learning, while discussed at length in the policy and other educational literatures is almost entirely absent from science education scholarship (exceptions include Bencze 2008, 2010; Carr and Thésée 2008; Carter 2005, 2008 and Tobin in this volume)

Sociocultural characterisations on the other hand, emphasise the divergence in local adaptations of larger global forces. Diversity, identity, cosmopolitanism, indigeneity, fragmentation, hybridity, deterritorialisation, mobility and interstitiality become the leitmotifs of the global age. There is pleasingly, more science education research tackling these complex issues. Indeed, any glance through the titles in this journal alone will identify articles from science education scholars that could just as easily have been collected together for several special issues under the umbrella of sociocultural globalisation. Here I speak of titles like Pauline Chinn's (2006), Preparing science teachers for culturally diverse students: Developing cultural literacy through cultural immersion, cultural translators and communities of practice, Maria S. Rivera Maulucci's (2008), Intersections between immigration, language, identity, and emotions: A science teacher candidate's journey, Glen S. Aikenhead and Masakata Ogawa's (2007), Indigenous knowledge and science revisited, Katherine Richardson Bruna and Roberta Vann's (2007) On pigs and packers: Radically contextualizing a practice of science with Mexican immigrant students, Ann Ryan's (2008), Indigenous knowledge in the science curriculum: avoiding neo-colonialism, and Sung Won Hwang and Wolff-Michael Roth's (2008), Learning science in an era of globalization: A phenomenology of the foreign/ strange, just to select a few.

Globalisation then, can be thought of as a complex dialectic of both political-economic and sociocultural transformations that are still to be fully configured even as they work themselves into the materiality of the everyday (Jameson 1998). Education (read science education) and globalisation are mutually implicative categories where globalisation acts as the macro-level sets of forces shaping the conditions for and being expressed within education, and education circulates and indigenises globalisation. Mapping these effects, let alone proactively addressing their inequities, is certainly science education's major challenge for the twenty-first century. With these thoughts in mind, one of my favourite quotes from the music group Mandalay opens this paper, as it seems to me that as scholars and contributors to this volume engaged in the work of research and writing, we are ever tugging at loose threads trying to gather them together in a way that not only adds some sensibility, but also invites us to action.

\section{Globalisation: a wicked problem?}

The term 'wicked problem' has entered the popular lexicon of late, migrating across from social and public policy areas. It describes 'insensible' complex issues that are highly resistant to resolution. One seems to notice it everywhere in Australia from where I writeoverheard in café conversations, referenced in academic settings, bandied about at parties, 
slipped into dialogue at dinner, and even making its way into politician's sound bites. While not usually referred to as such, to my mind, a wicked problem is an apt descriptor of globalisation.

The notion of the wicked problem was first proposed in 1973 by the urban planners Rittel and Webber from the University of California, Berkley to describe the inability of the paradigmatic mode of technical rationality to tackle real-life conditions that are complicated, uncertain, and unstable. Their choice of term was interesting given that 'wicked' is usually taken to be a designation of evil or wrongdoing. However, the Oxford Dictionary suggests that one of its meanings dating back to 1352 is 'difficult to do something with'. Presumably employing this variant of the word, Rittel and Webber (1973) provided 10 criteria for characterising a wicked problem. These might be summarised as consisting of dynamic and interlocking issues that lack definitional clarity because multiple stakeholders in shifting social contexts have different interpretations and seek different outcomes. Clearly challenging, a Google search of wicked problems throws up a plethora of examples that includes climate change, land degradation, indigenous rights, the global financial crisis, GM foods, health care, the 'war on terror', and the governance of science and technology just to mention a few. More recently, the 2007 Australian Public Service (APS) document entitled Tackling Wicked Problems: A Public Policy Perspective has reinterpreted the criteria. This listing has not necessarily made wicked problems any easier to deal with but extracting them here at length possibly makes them a little more sensible:

Wicked problems are difficult to clearly define. The nature and extent of the problem depends on different stakeholders hav(ing) different versions of what the problem is. The debate concerning the causes, the extent and the solutions to climate change is a good example.

Wicked problems have many interdependencies and are often multi-causal. There are also often internally conflicting goals or objectives within the broader wicked problem. It is the interdependencies, multiple causes and internally conflicting goals of wicked problems that make them hard to clearly define.

Attempts to address wicked problems often lead to unforeseen consequences. Because wicked problems are multi-causal with many interconnections to other issues, it is often the case that measures introduced to address the problem lead to unforeseen consequences elsewhere.

Wicked problems are often not stable. Frequently, a wicked problem and the constraints involved in understanding the problem are evolving at the same time that policy makers are trying to address the problem. Policy makers have to focus on a moving target.

Wicked problems usually have no clear solution. As there is no definitive problem, there can be no definitive solution. Problem-solving often ends when deadlines are met, or as dictated by other resource constraints rather than when the 'correct' solution is identified.

Wicked problems are socially complex. It is a key conclusion of the literature around wicked problems that the social complexity of wicked problems, rather than their technical complexity, overwhelms most current problem-solving and management approaches. 
Wicked problems hardly ever sit conveniently within the responsibility of any one organisation. Even if the solution is opaque, it is clear that it involves many organisations.

Wicked problems involve changing behaviour. The solutions to many wicked problems involve changing the behaviour. The range of traditional levers used to influence citizen behaviour-legislation, fines, taxes, other sanctions-may not be sufficient. More innovative, personalised approaches are likely to be necessary.

Some wicked problems are characterised by chronic policy failure. Some longstanding wicked problems seem intractable (APS p. 3-5).

One can't help but think of that wonderful quote from Laurence J. Peter of the Peter Principle fame who chimed, '[s]ome problems are so complex that you have to be highly intelligent and well informed just to be undecided about them!' Surely globalisation is such an example par excellence. It matches all the criteria set out above, characterised as it is by its multicausal, multidimensional and transdisciplinary nature, its instability, its social complexity, its forced behavioural change, and its endemic climate of uncertainty. Looking a little deeper into some of the wicked problems already identified, we can see that globalisation underpins and is responsible for, many of them. Indeed, globalisation may itself be the $u r$-problem, that is, the wickedest of a wicked bunch. Taking an overt ideological and political stance, and given its origins in the spread of Eurocentric modernity, some readings might even regard globalisation as the 'Wicked Witch of the West'!

Not only can globalisation be conceived as a wicked issue, but our recognition of other wicked problems is a likely outcome of globalisation at work. As the authors of the APS (2007) contend, "[t]he expansion of democracy, market economies, ... travel and social exchanges may have highlighted value differences, weakened traditional authority and control mechanisms, and promoted dissensus rather than consensus in the problem-solving process" (p. 6). It is this dissensus taken in from a global perspective that heightens the complexities and difficulties of much of the contemporary world.

The APS 2007 document goes on to contend that "[t]ackling wicked problems is an evolving art" (p. 35). Recognising that definite solutions are unlikely, the document nevertheless suggests both approaches and strategies for their consideration. New mechanisms of holistic thinking that are capable of grasping the big picture including underpinning factors and their interrelationships, the toleration of uncertainty with a broad understanding that there are no quick fixes, multidisciplinary and transdisciplinary approaches to garner all perspectives, and more collaborative and innovative approaches that are highly adaptive, seem to be what is required. Clearly, business as usual won't do, as " $[\mathrm{b}] \mathrm{y}$ their nature, the wicked issues are imperfectly understood, and so initial planning boundaries that are drawn too narrowly may lead to a neglect of what is important in handling the wicked issues" (APS 2007 p. 11). This is similar to the thought often attributed to Albert Einstein that we cannot solve problems by utilizing the same kinds of thinking that created the problems in the first place.

If we conceptualise globalisation as a wicked problem, then its intersection with science education is rendered equally wicked. Clearly, the task of elaborating globalisation and science education requires a reimagining of the conceptual spaces in accordance with the ideas from the APS (2007) document. This is necessary to avoid Jessica Benjamin's observation that, even if one adopts an oppositional stance, the prior constructs so shape one's starting point and holds on to one's coordinates of thought, that rejecting the 
postulates doesn't seem to be enough (Benjamin 1996). We take from this that staying within conventional science education space means that globalisation at best, becomes a 'bolt-on' topic to be added to an already ossifying list of time-honoured imperatives ill suited to the demands of the twenty-first century. Rather, as David Harvey (2010) argues, all academics and researchers of whatever domain should be alert to 'the times', and debate the complexities of the interconnections between political, economic, social and cultural imperatives that form our contemporary 'wicked' world. Harvey (2010) contrasts this approach with the localism of many scholars, which Jay Lemke (2001) suggests includes those within science education, who incrementally advance their own idiosyncratic fields as if they were enshrouded in a vacuum. Like Lemke (2001), I believe that science education has not looked enough at the impact of the changing theoretical and global landscape by which it is produced, requiring it to look well beyond its own discourses if it is to remain relevant into the future.

As globalisation brings with it a new and heightened visibility of different accounts of global history and various alternative modernities relegating the presently dominant Western view (but for how long given the rise of China and India?) to that of just another narrative, we need to bring to the task of sensibility new and different approaches and strategies such as those suggested by the APS (2007) document. These would emphasise global variability, global connectivity, and global justice through constructs such as diversity, identity, hybridity, social and ecological justice, interstitiality, other knowledges, multiculturalism, cosmopolitanism and the like. It would also work to dissemble the neoliberal social and economic policy regime that is the world's current orthodoxy. I think the papers in this volume that tackle some of these issues particularly in the context of urban science education, go some ways towards moving science education into this new and overdue conceptual space. Collectively, they engage with the ways globalisation works itself into the materiality of the everyday science classroom utilising key globalisation postulates including identity, diasporas past and present, multiculturalism, social justice, equity, hybridity and neoliberalism amongst others. Just how successful the papers are at this task is for readers to decide.

\section{Outlining the original contributions}

Our first paper is from Gale Seiler from McGill University who utilises a narrative approach to explore the experiences of Donna, Lucy and Wayne, three African American preservice science teachers attempting to inhabit in their new roles. Gale's intersection with globalisation is with the ethical project of cosmopolitanism, an ideology that seeks inclusivity in moral, economic and political relationships between diverse racial and cultural groups. She argues for the role of science education to "advanc(e) cosmopolitanism as a more hopeful ideology and one more aligned with the orientation to social justice and equality of rights and opportunities." Gale's exploration of preservice teachers of colour works against their experiences of exclusion from the dominant culture of schooling and the 'mystique of Western science.' She describes how Donna, Lucy and Wayne have developed connections with science from their youthful or adult experiences external to school. They are able to employ these connections to form hybridized identities-in-action as science teachers in a type of creolized approach to teaching. Gale explains her view of creolized science in one of her footnotes:

Hybrid science identities among students and teachers signal the generation of a creolized form of science; similar to creolized languages, creolized science provides 
new opportunities for communication and participation for those who contribute to it and employ it. Emerging from situations of diaspora, creolized forms of science would combine (a) existing practices and symbols of science culture, (b) new practices and symbols of science culture and (c) possibilities for expanded action both in science and in other fields (Elmesky and Seiler 2007).

Gale ultimately argues that science teachers of non-dominant students need to enact hybridized identities and creolized science teaching to facilitate student identification rather than dis-identification with science. This can occur she believes, through the gradual (re)construction of the culture of science education by conscious participation in the lives of students. As globalisation forces teachers to engage with increasing cultural diversity, Gale's paper reminds us of our challenges and provides some useful suggestions for action.

We next hear from Rowhea Elmesky. Rowhea critiques the static nature of educational systems at large and the inability of the enduring canonical science curriculum to meet the needs of the marginalised in the global era of increasing cultural diversity. She grapples with engaging students of colour in science classes, and like Gale, looks to hybridized identities and creolized forms of science as strategies to help her students experience success. Rowhea tells the story of the ways Ivory, Shakeem, Randy, May and other student researchers used their oral cultural capital (after Bourdieu) in the form of rap practices to develop their understanding of science concepts. This approach Rowhea argues, "promotes students' empowerment or agency as they build social and symbolic capital ... (when) ... able to utilize rap in relation to science-either to build understandings or represent the concepts they have grasped, they introduce new forms of science-creolized forms and experience the hybridization of their identities. That is, they begin to perceive new possibilities of who they are and can be in relation to school science ...". Rowhea provides readers with another powerful example of a way to move science education into that new conceptual space.

We next move on to Wesley Pitts. Wesley reviews the global as well as the macrolmesolmicro fields in which the cultural production of science education occurs. At a global level, he identifies the federal neoliberal policy of No Child Left Behind as shaping the benchmarking that ultimately students like Amber, Diamond, Angel and their teacher Rey need to master in their New York urban setting. Within the smallest field, Wesley investigates one particular acid-base experimental procedure, taking precise and detailed micro-measurements of "physical and verbal displays of synchrony, mutual focus, entrainment, and emotional energy, body gestures, and prosody markers" to provide empirical evidence of "productive ways (the students) build solidarity and interstitial culture across salient social boundaries." Like the two preceding studies, Wesley attempts to promote strategies that marginalized students of colour can utilise to engage the dominant science curriculum and make it more accessible.

The final original paper comes from Ken Tobin recognised by readers of this journal and more broadly as an eminent educator, who reflects on some of his own perhaps less well known experiences in science education. Ken focuses on two temporally and geographically discrete points across a long career, science education in Western Australia during the 1960s where he began as a teacher and Philadelphia in 2005, where he endeavoured to learn more about urban education. In these two spaces, Ken utilises an historical auto ethnography methodology to examine how global referents mediate the production of contemporary science education. Specifically, he 'pulls out the threads' that illuminate how neoliberal imperatives have shaped science education through the types of science education offered, as well as the measures of accountability that can not only hinder authentic 
learning, but do little to address endemic poverty and disenfranchisement. In Western Australia, Ken describes the processes coming from firstly, England with a direct link back to Ernest Rutherford and the Cavendish laboratories at Cambridge University and then, the USA through the Harvard University's Project Physics, to reform the science education curricula in line with global trends in what is known as one of the world's most distant city-Perth. In Philadelphia, Ken describes the impact of neoliberal policy on a school known by the pseudonym City High as it undergoes various configurations consequent to these policy implementations. His goal he suggests, was to illustrate how "neoliberal hegemony mediates science education locally."

\section{Urbanism, location and global mobilities}

As noted above, each of these four papers includes examples of globalisation at work in contexts of urban science classrooms. Collectively, these contexts lie within that highly populated and racially diverse corridor in the USA between New York and Baltimore/ Washington (Gale talks of Baltimore, Ken and Rowhea of Philadelphia, and Wesley of New York). Many readers will share with me a lack of familiarity with these contexts and their particular issues. Nevertheless, globalisation being what it is allows us some insight into these experiences. I refer here to the ways that visual media like film and television exported internationally fosters the global imaginary making us feel connected to far-flung places and other lived cultures (writing from Melbourne, these places are indeed farflung!). My most recent vicarious experience of these settings comes from the critically acclaimed US television series The Wire, filmed in Baltimore from 2002 to 2008. Season 4 of The Wire includes a story line set within a city classroom, and reading the papers for this issue on urban science education puts me in mind of the struggles of mathematics teacher, Mr Prez.

Season 4's Episodes 9 and 10 of The Wire graphically depict globalisation at work through market regulatory mechanisms in the form of standards/benchmarking similar to those discussed by Wesley and Ken. Having made progress in engaging the marginalised students of colour in the educational process, Mr Prez is confronted with the inanity of turning his maths classroom over to practising language arts test items. He is required to implement long class periods (with the classroom heating turned up to a temperature that keeps the class docile) and 'teach to the test' so as the school may raise its scores under the No Child Left Behind's regime. As a former police man, Mr Prez likens the stupidity of the exercise to the moral corruption of smudging the Baltimore Police Department crime statistics so that individual Commanders 'look good' with apparent lower crime rates while the streets remain as troubled as ever. As the students struggle to practice test items under the watchful eye of a local education authority representative who proclaims her belief in education as being tested in the standardised school curriculum, Mr Prez colludes with the class to engage in minimal test preparation. Rather, they get down to the real business of education. In the context of this particular group of urban youth, this includes knowledge and skills in managing money for buying, selling and profit-making on the street, probability theory to help cope with the local dice games that are a permanent feature of life, using the internet, general reasoning, healthy practice of all types and other mathematics for living. The sympathy of the viewer is firmly with the students and Mr Prez who are struggling to make something of their opportunities in the circumstances of Baltimore street life. The imperatives and politics of standardised curriculum and testing are 
portrayed, as they should be, as being part of a wider agenda we can see as globalisation that have little to do with the students' real needs.

Mr Prez's approach acts as another instance of urban education for marginalised students of colour within the New York-Washington corridor that carries with it a sense of place. Place as a primary container or basic unit of social research and analysis needs to be reconfigured Tom Hall (2009) argues, to cope with the fluidity of the mobile globalised world. Ideas of place, space, location, terrain, and landscape are being rapidly reconceptualised by globalisation into a type of 'new mobilities' paradigm of flows and deterritorialisation within the fields of anthropology, sociology, geography, cultural studies, and science and technology studies. The result is a new "trans- and post-disciplinary urbanism, which, while clearly aligned with the spatial and mobilities turns, also make space for a continuing-intensified and re-energized-appreciation of place" (Hall 2009, p. 574). In this way, studies such as those in the original papers can be both emplaced as well as speak to global processes beyond the bounds of their locations. Wesley acknowledges the dynamic simultaneity of global through to local fields in his paper, not in the sense of nested hierarchies, but as overlapping scales of interaction that focuses our attention on relational processes. Ken also acknowledges the challenges of the spatiality of the scales with which we need to operate when he commented that "(i)rrespective of social structures that are germane to Philadelphia, science education is intended to bear a family resemblance to fields bearing the same name anywhere in the world. Specifically, I address the näive expectation that teachers can teach and youth can learn in much the same ways throughout the global community." The conceptual leaps involved in the simultaneity of emplacement, deterritorialisation and mobility hark back to the characteristics of wicked problems that require holding instability and uncertainty in tension with embodied actions. Nevertheless, this is what is required to truly meet the challenges of globalisation for science education and avoid it becoming a 'bolt-on' topic in an already overcrowded field. Just how we do this as a professional community is like all wicked problems -a work in progress!

\section{The essayists}

Regular readers of CSSE will understand that its format generally incorporates a 'forum' where invited scholars are enlisted to open up the dialogue and extend the ideas of the original articles in a particular volume. Sonya Martin in her editorial to the second volume of this series outlines again this unique CSSE approach (Martin 2010). Sonya goes onto describe how she systematically recruited international scholars to respond to the four core articles on globalisation and science education such that diverse views from across the world were well represented. In a less systematic but by no means less thoughtful way, as guest lead editor of this volume I have invited commentators whose fields are either outside of science education or include other areas of specialisation along with science education, to write reflective essays on one of the original articles of this volume. My suggestions to the commentators was to utilise the Gilles Deleuze and Félix Guattari's (1987) conceptual notion of 'lines of flight' when considering their responses. Big or small, Deleuze and Guattari's 'lines of flight' pull the threads out and beyond the dominant paradigmatic thinking, enabling creative escapes and divergent responses. This was a deliberate rhetorical strategy to facilitate the move towards a new and overdue conceptual space for science education described above as better suited to the 'wickedness' of globalised contemporaneity. Moreover, utilising the response essays as divergent thinking acts as a 
metaphor for globalisation itself, that complex disjointed process as opening and proliferating as it is simultaneously closing and homogenising. The outcome is a range of articles canvassing many of globalisation's postulates that relate to education more generally.

What these commentators all share beyond their expertise in globalisation theory and practice is that they are writing from Australia. My choice to use Australian scholars here is quite purposeful. I developed the idea when I read Ken's analysis of globalisation at work in Western Australia, and I was reminded that Perth is one the world's most isolated cities, something all Australians appreciate particularly when we enjoy some of the world's few remaining pristine ecoscapes that surround its urban spaces. Australia is both literally and figuratively a long way from the centre from which globalising forces emanate. It is in the unique position of being a modern and affluent Western democracy with all the economic/political, sociocultural and technoscientific capital available under globalisation. It is geographically Asian, multicultural in demographics and with strong cultural referents back to the United Kingdom. The indigenous Australians (Australian Aboriginals) are the oldest continuous human culture in the world. Our more recent settler-state history casts us as a postcolonial society with all the multiple identities and fusions that that entails, yet we live within the most ancient and eroded landscape on Earth. We are an English-speaking outpost, globalisation's language of choice, but as voracious travellers we also know the world. With only about 22 million consumers despite our affluence, we are too small a market to figure too significantly on the global radar. Nonetheless, our massive natural resources in iron, coal, uranium and the like provide many countries, particularly our largest trading partner China, with the wherewithal to fuel the world's market economy. The raw materials trade along with our tightly regulated financial sector ensured we were the only developed country to avoid recession in the recent financial crisis. This cultural and geographical positioning gives us a sense of looking back from the periphery with perhaps the allusion that we can select from the array of what is on offer. Together, these features afford Australians a significant amount of conceptual distance and space, allowing our scholars a distinctive perspective on how globalisation works its way into the materiality of the everyday.

Our first essayist is Bill Atweh from Curtin University who responds to Gale Seiler's paper. A well-published mathematics educator, Bill received an Australian Research Council grant to investigate globalisation and internationalisation within mathematics education. He also edited a book on globalisation entitled Internationalisation and Globalisation in Mathematics and Science Education. Bill pulls at the threads of race, ethnicity, social justice, identity and ethics within Gale's paper, taking them in theoretical lines of flight to somewhere else. His focus on social justice is derived from his belief that Gale's aim is to obtain social justice for marginalised groups. Likewise his choice of identity is due to Gale's use of the construct as a tool of analysis though Bill sees this as problematic. Bill's discussion of ethics is for me however, the highlight of his paper. He draws from Lithuanian-born, French philosopher Emmanuel Levinas who argues for ethics to be the 'first philosophy,' and lived out in our responsibility for the other. The traditional philosophical quest for knowledge is but a secondary pursuit to the more basic ethical duty to the other. This fits with Gale's ethic of cosmopolitanism and is foundational to the way Bill sees how the other four constructs may be justly employed within education. It is a thoughtful paper that offers much to the reader.

Annette Gough from RMIT University in Melbourne responds to Rowhea Elmesky. Annette is a well regarded environmental and science educator with an interest in globalisation who has also published in the area of gender. Annette's review essay places 
Rowhea's contribution in the juncture of youth disengagement with science, multicultural education and globalisation, with an underlay of a historical context and critiques of science education from feminist and postcolonial perspectives. Annette recognises Rowhea's use of rap as a means of engaging students with science in a type of creolised science practice. However, she believes that Rowhea misses an important opportunity to ask questions of the science itself: "the value of Western science for these students is not interrogated, despite several decades of critique of Western science by feminist and postcolonial researchers." Annette suggests that while creolised science is a type of cultural globalisation, the globalisation of science as an acultural artefact is left as a given. For Annette and indeed many other scholars, globalisation requires the dissembling of science (read Western science) itself as epistemological diversity begins to become as apparent as cultural diversity. Annette also queries the universality of rap music in a discussion that echoes the dilemmas of emplacement and deterritorialisation above.

Our next essayist is Noel Gough from LaTrobe University who responds to Wesley Pitt's paper. Noel, as a former editor of the Journal of Curriculum Studies is a curriculum theorist of regard and an environmental educator with expertise in science education and globalisation. In his response essay, Noel chooses three distinct, and what some may regard as obscure, 'lines of flight' from Wesley's paper in a faithful homage to Deleuze and Guattari (1987). He attempts to open up 'small ruptures' that facilitates new connections and alternative directions for science education research. Noel focuses firstly, on Wesley's discussion of the 'scrubs shirt' as a globalised symbol of medical sciences and services. Through this motif, Noel develops a postcolonial critique of Western science as it is represented by the medical sciences. Secondly, Noel queries the idea that recipe-based school laboratory work can be called experimentation. He suggests such tasks that are required to meet standards or benchmarking criteria in a neoliberal take on education, distort the ways in which science is really enacted. Thirdly, Noel takes up Wesley's use of the Sheffer stroke 'l' in an intense discussion on dialectical categories. Noel closes his essay with the following comments: "I have taken (Wesley's) paper as an invitation to explore some alternative directions for science education research in the genre his study exemplifies. I try to write in the spirit of Deleuze's (1995) encouragement for 'writing to bring something to life, to free life from where it's trapped, to trace lines of flight' (pp. 140-1) and, whether or not I have succeeded in this instance, I thank Wesley Pitts for provoking me to embark on another attempt to do so."

Our final essayist is Joseph Zajda, a social scientist at the Australian Catholic University, who responds to Ken's article. Joseph's extensive experience in the issues of globalisation and education include the production of a twelve volume book series for Springer entitled Globalisation, Comparative Education and Policy Research, several titles of which analyse globalisation. Building upon Ken's focus on neoliberalism, Joseph takes up the themes of access, equity and social stratification but from a more broadly based educational policy perspective. Joseph provides us with a range of chilling data from the Organisation for Economic Co-operation and Development (OECD) that reminds us of the asymmetrical and stratified impact of globalisation on education. There is a great paucity of this type of comparative policy work within science education research. Indeed, looking back over the long stretch of his career, Peter Fensham identifies it as the great gaping hole (Fensham 2008). Joseph also reminds us of the need to analyse our assumptions about globalisation:

When, for instance, a writer or a seminar speaker uses the word 'globalisation' in a pedagogical and educational policy context, one wonders what assumptions, be they 
economic, political, social and ideological, have been taken for granted, and at their face value-uncritically, as a given, and in this case, as a globocratic (like technocratic) phenomenon. The politics of globalisation, particularly the hydra of ideologies, which are inscribed in the discourse of globalisation, need to be analysed critically, in order to avoid superficial and one-dimensional interpretations of the term.

Taking Joseph's caution seriously will help science educators' avoid the tendency to 'bolton' globalisation to our topics of current interest.

Our last paper comes from Phil Clarkson, a mathematics educator with extensive experience also from the Australian Catholic University. Phil's contribution to this special volume is to draw together the 'threads' of the original articles and the reflection essays to make something 'sensible'. Phil was Bill's co-researcher in the Australian Research Council award investigating globalisation and internationalisation within mathematics education. Phil borrows from Ken's paper and uses autoethnography to describe selected vignettes from his experiences as a scholar in multi-lingualism and mathematics education across a variety of global contexts. Through these he is able to explore small ruptures in his thinking of which he was unaware at the time, and with which he now finds echoes in all of the papers in this special edition. Two 'lines of flight' emerge from Phil's vignettes. Firstly, he notes that multilingualism, essential for understanding globalisation and cultural diversity, doesn't receive as much attention in the science education literature as it might. Secondly, he highlights the silences surrounding Western knowledges as unchallenged cultural artefacts identified too by Annette and Noel as essential issues for science education scholarship in globalisation. They all feel that creolised science is not a robust enough concept to undertake the necessary dissembling of Western science in the globalised age. Finally, Phil notes that globalisation has bought with it often confronting and daunting choices for teachers, underpinned by values we may or may not be able to articulate. While daunting for contemporary educators, he believes these processes can nevertheless be exhilarating.

\section{Making a 'wicked' problem a little more sensible}

I hope readers enjoy this special issue of papers on globalisation and science education and see it as just one more 'way station' in the progress towards a new conceptual space for science education better suited to the demands of the twenty-first century. We face enormous challenges in grappling with these wicked problems but with the goodwill within the science education community displayed by the scholars whose work is represented within the pages of this volume, we are at least in with a chance!!

\section{References}

Aikenhead, G., \& Ogawa, M. (2007). Indigenous knowledge and science revisited. Cultural Studies of Science Education, 2, 539-591.

Atweh, B., Borba, M., Calabrese Barton, A., Clark, D., Gough, N., Keitel, C., et al. (Eds.). (2007). Internationalisation and globalisation in mathematics and science education. Dordrecht, The Netherlands: Springer.

Australian Public Service. (2007). Tackling wicked problems: A public policy perspective 
Bencze, J. L. (2008). Private profit, science and science education: Critical problems and possibilities for action. Canadian Journal of Science, Mathematics \& Technology Education, 8, 297-312.

Bencze, J. L. (2010). Exposing and deposing hyper-economized school science. Cultural Studies of Science Education, 5, 293-303.

Benjamin, J. (1996). Like subjects, love objects: Essays on recognition and sexual difference. New Haven, NJ: Yale University Press.

Bruna, K. R., \& Vann, R. (2007). On pigs and packers: Radically contextualizing a practice of science with Mexican immigrant students. Cultural Studies of Science Education, 2, 19-59.

Carr, P. R., \& Thésée, G. (2008). The quest for political (il)literacy. In B. Porfilio \& C. Malott (Eds.), The destructive path of neoliberalism (pp. 233-256). Rotterdam, The Netherlands: Sense Publishers.

Carter, L. (2005). Globalisation and science education: Rethinking science education reforms. Journal of Research in Science Teaching, 42, 561-580.

Carter, L. (2008). Globalisation and science education: The implications for science in the new economy. Journal of Research in Science Teaching, 45, 617-633.

Chinn, P. (2006). Preparing science teachers for culturally diverse students: Developing cultural literacy through cultural immersion, cultural translators and communities of practice. Cultural Studies of Science Education, 1, 367-402.

Delanty, G. (2000). Citizenship in a global age: Society, culture, politics. Buckingham: UK: Open University Press.

Deleuze, G., \& Guattari, F. (1987). A thousand plateaus: Capitalism and schizophrenia (B. Massumi, Trans.). Minneapolis: University of Minnesota Press.

Hall, T. (2009). Footwork: Moving and knowing in local space(s). Qualitative Research, 9, 571-585.

Harvey, D. (2010). The enigma of capital and the crises of capitalism. Talk given at the University of California at Berkeley, October 8, 2010.

Hwang, S. W., \& Roth, W.-M. (2008). Learning science in an era of globalization: A phenomenology of the foreign/strange. Cultural Studies of Science Education, 3(4), 937-958.

Jameson, F. (1998). Notes on globalization as a philosophical issue. In F. Jameson \& M. Miyoshi (Eds.), The cultures of globalization (pp. 33-54). Durham, NC: Duke University Press.

Lee, Y.-J., \& Roth, W.-M. (2008). Science education in an era of globalization: An introduction. Cultural Studies of Science Education, 3, 313-315.

Lemke, J. (2001). Articulating communities: ociocultural perspectives on science education. Journal of Research in Science Teaching, 38, 296-316.

Mandalay. (1998). Insensible [Song]. Empathy. Virgin Records.

Martin, S. (2010). "Act locally, pubish globally": International/multidisciplinary research efforts needed to understand the impact of globalization on science education. Cultural Studies of Science Education, 5 , 263-273.

Maulucci, M. S. R. (2008). Intersections between immigration, language, identity, and emotions: A science teacher candidate's journey. Cultural Studies of Science Education, 3, 17-42.

Rittel, H., \& Webber, M. (1973). Dilemmas in a general theory of planning. Policy Sciences, 4, 155-169.

Ryan, A. (2008). Indigenous knowledge in the science curriculum: Avoiding neo-colonialism. Cultural Studies of Science Education, 3, 663-702.

The Wire. (2006). Television series. USA: HBO.

Zajda, J. (2006). The international handbook globalisation and education policy research. Dordrecht, The Netherlands: Springer.

\section{Author Biography}

Lyn Carter currently lectures in science and technology education to undergraduate primary and secondary teacher education students at the Trescowthick School of Education, Australian Catholic University. She also lectures in postgraduate education particularly in the areas of research methods and contemporary issues in curriculum. Her current research focuses on the broader influences on science education, and the use of cultural theory as a way of expanding research within science education. She has written extensively in this area. Lyn recently received an Australian Learning and Teaching Council citation for her teaching. 